\title{
LEVANTAMENTO QUALI - QUANTITATIVO DA ARBORIZAÇÃO URBANA DO DISTRITO DE RAFAEL ARRUDA, SOBRAL, CE
}

\author{
Leiriane Moura de Sousa ${ }^{1}$; Marlene Feliciano Figueirêdo ${ }^{2}$ Petrônio Emanuel Timbó Braga ${ }^{3}$
}

\section{RESUMO}

O presente trabalho teve como objetivo reconhecer o cultivo das espécies exóticas, fazer um levantamento qualiquantitativo e um fitossanitário da arborização do Distrito de Rafael Arruda, CE, a fim de nortear sua reestruturação e verificar a qualidade da vegetação. O trabalho foi realizado no Distrito de Rafael Arruda, $45 \mathrm{~km}$ da sede Sobral, Ce no período de fevereiro a novembro de 2012. Foram analisados 1.546 indivíduos arbóreos pertencentes a 32 espécies distribuídas em 15 famílias. Foi verificado que Fabaceae apresentou maior diversidade florística com $38 \%$, das espécies encontradas, seguida de Anacardiaceae com 13\%. Foram registrados $72 \%$ de espécies exóticas e $28 \%$ de nativas. Considerando o estado físico e fitossanitário dos espécimes foi constatado que $73,54 \%$ das mesmas se apresentaram em bom estado, $22 \%$ apresentaram ataques brandos de pragas e 3,82\% foram incluídas na condição ruim. Quanto aos insetos, foram identificados as seguintes ordens Thysanoptera, Hemiptera, Hymenoptera, coleóptera e Homoptera, sendo que os insetos que causaram mais danos as árvores na estação inverno são da ordem Thysanoptera, enquanto no verão foi a Homoptera, atacando mais as espécies exóticas. A arborização do Distrito caracteriza-se pela alta frequência de espécies exóticas, podas emergenciais e baixas diversidades florística.

Palavras chave(s): Manejo; Espécies exóticas; Fitossanidade

\section{QUALI-QUANTITATIVE SURVEY OF URBAN ARBORIZATION OF THE DISTRICT OF RAFAEL ARRUDA, SOBRAL, CE}

\begin{abstract}
The present study aimed to recognize the cultivation of exotic species, make a qualitative and quantitative survey and a plant of afforestation District Rafael Arruda, CE, to guide its restructuring and check the quality of vegetation. The work was conducted in the District of Rafael Arruda, $45 \mathrm{~km}$ from Sobral-Ce in the period from February to November 2012. Were analyzed 1,546 arboreal individuals belonging to 32 species distributed in 15 families. It was found that Fabaceae showed the highest floristic diversity with $38 \%$ of the species found, followed by Anacardiaceae with 13\%. Were recorded $72 \%$ of exotic species and $28 \%$ of native. Considering the physical state and phytosanitary of the specimens was found that $73.54 \%$ of them presented themselves in good condition, $22 \%$ presented mild attacks of pests and $3.82 \%$ were included in bad condition. As insects have been identified the following orders Thysanoptera, Hemiptera, Hymenoptera and Homoptera, coleóptera, and insects that have caused more damage to the trees in the winter season are of the order Thysanoptera, while in the summer was the Homoptera, attacking more the exotic species. The urban afforestation of the District is characterized by the high frequency of exotic species, emergency trim and low floristic diversity.
\end{abstract}

Keyword (s): Manage; Exotic species; Phitosanity

\footnotetext{
1 Graduanda em Biologia. Universidade Estadual Vale do Acaraú, Sobral. Ceará. leirianemoura@gmail.com

2 Profa. Adjunta do Curso de Biologia. Hérbario Professor Francisco José de Abreu Matos. Universidade Estadual Vale do Acaraú, Sobral. Ceará. mfmufpb@yahoo.com.br

3 Prof. Adjunto do Curso de Biologia. Laboratório de Biologia Animal. Universidade Estadual Vale do Acaraú. Sobral. Ceará. espcbiuva@hotmail.com

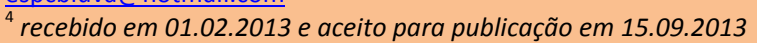


Atualmente, a maioria da população humana vive no meio urbano e com a permanência neste meio vem necessitando, cada vez mais, de condições que possam melhorar a convivência dentro de ambientes muitas vezes adversos. Neste sentido a população passou a dar mais importância à arborização das cidades, que é o que tem de mais próximo para tornar um ambiente ameno e saudável.

A arborização urbana em vias públicas é fundamental para a manutenção da qualidade de vida, contribui com a estabilização climática, diminui a velocidade dos ventos, embeleza, fornece abrigo e alimento à fauna, produz sombra e lazer às ruas e avenidas das cidades. Contudo, quando não há planejamento da arborização, inúmeros problemas podem ocorrer e ao invés de um elemento benéfico, a arborização passa a representar um foco de conflito nas cidades.

Para que a vegetação urbana seja mais eficiente, o planejamento da mesma deve considerar as características das espécies vegetais em relação ao espaço disponível. Este deve ser elaborado de forma que não cause danos aos vegetais e que não entre em conflito com a infraestrutura urbana (BOENI; SILVEIRA, 2011).

O uso de espécies nativas no planejamento da arborização deve também ser priorizado, considerando que as espécies exóticas podem causar danos ao ambiente, perda da biodiversidade e alteração da paisagem natural (ZILLER, 2001).

É comum a comunidade ignorar a diversidade de espécies nativas apropriadas para a arborização privilegiando as exóticas. No Brasil, este fato é freqüente. Santos (2000) encontrou comportamento semelhante na arborização de Belo Horizonte, MG. Carvalho (2004) menciona que mais de $80 \%$ das árvores existentes nas ruas das cidades brasileiras são da flora exótica. Este último autor argumenta que os motivos que levaram a essa situação são o desconhecimento de nossas espécies e a origem colonialista do Brasil, quando diversas espécies foram trazidas de outros países para arborizar nossas ruas e praças.

Quando a arborização já está implantada, a diversidade, a heterogeneidade e o cálculo da frequência das espécies utilizadas são de suma importância para evitar os riscos relacionados à fitossanidade, devido ao ataque de pragas e doenças. Isto se faz necessário para garantir o máximo de proteção aos indivíduos vegetais, difundindo e valorizando a flora brasileira e consequentemente favorecendo a sobrevivência da fauna nativa (SANTAMOUR-JUNIOR, 2002).

Desse modo, o presente trabalho objetivou reconhecer o cultivo das espécies exóticas, fazer um levantamento quali-quantitativo e um fitossanitário da arborização do Distrito de Rafael Arruda em Sobral, CE, a fim de nortear sua reestruturação e verificar a qualidade da vegetação. 


\section{METODOLOGIA}

\section{Área de estudo}

O estudo foi realizado no Distrito de Rafael Arruda localizado no norte do Estado do Ceará situado a 45 $\mathrm{km}$ da sede Sobral nas coordenadas geográficas aproximadas de $3^{\circ} 50^{\prime} 9^{\prime \prime} \mathrm{S}, 40^{\circ} 40^{\prime} 4^{\prime \prime} \mathrm{W}$, limitado pelos municípios de Mucambo, Cariré e Coreaú, sendo constituído por quatorze vias públicas, três praças e por três povoados: Pedrinhas, Ouro-branco e Recreio (Figura I).
O Clima da área em estudo é do tipo tropical Quente Semiárido. A temperatura anual é $30^{\circ} \mathrm{C}$, com breve variação nas médias mensais. A pluviosidade média anual é de $854 \mathrm{~mm}$ irregularmente distribuída entre os meses de janeiro e junho, com maior incidência entre janeiro a maio. Sua vegetação, predominante é a caatinga arbustiva (CEARÁ, 2011).

Figura 1. Localização do Distrito de Rafael Arruda, Sobral, CE, Brasil, 2012

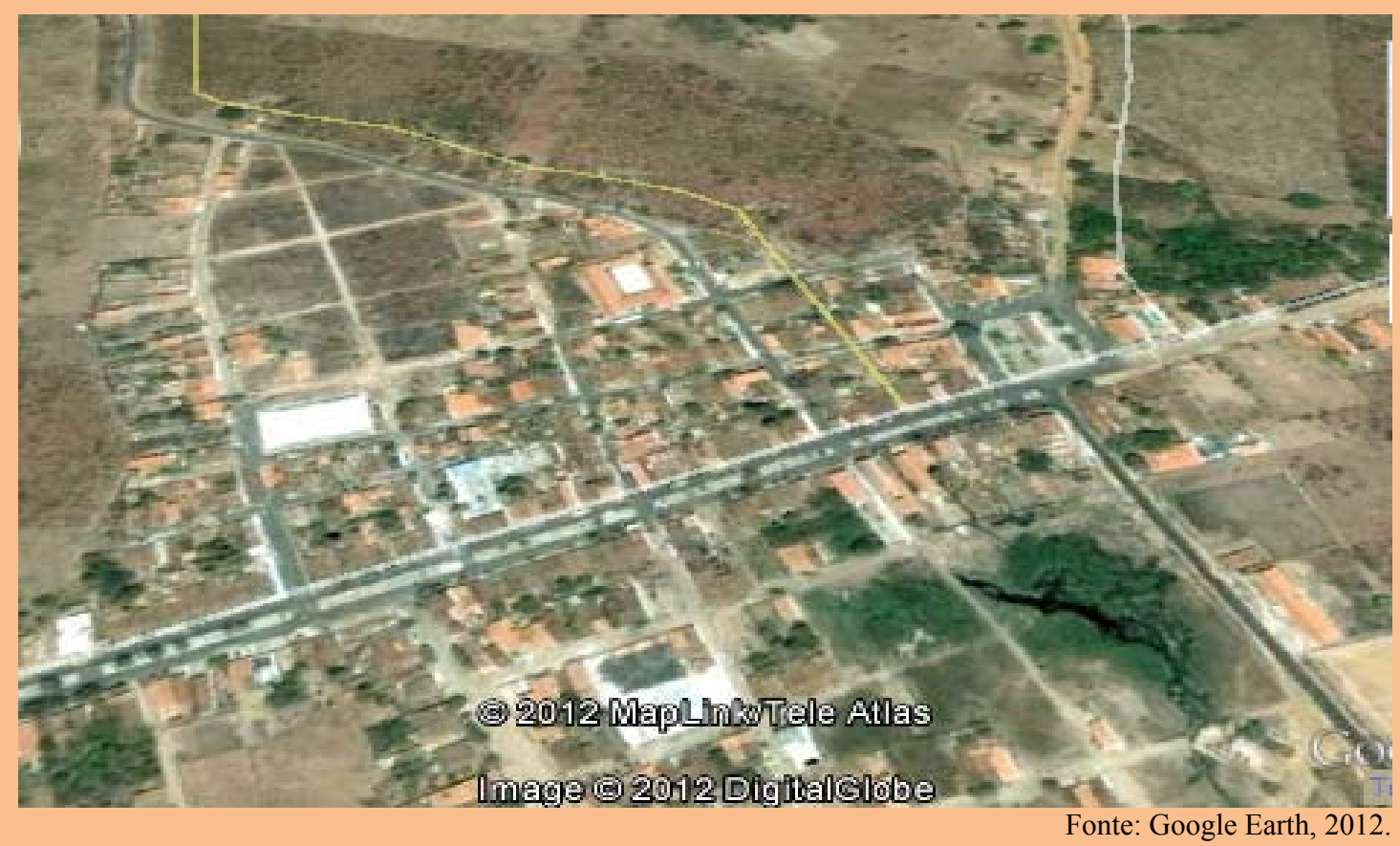

\section{Levantamento das espécies arbóreas e diagnóstico qualitativo}

O levantamento florístico da área foi realizado no período de fevereiro a outubro de 2012, através da coleta de três amostras férteis por espécie, secagem, identificação e a incorporação de exsicatas no Herbário Francisco José de Abreu Matos (HUVA). Para secagem do material botânico, foi utilizada estufa com temperatura de $45^{\circ} \mathrm{C}$ por um período de três dias sendo posteriormente levado ao freezer para choque térmico por 72 horas conforme as técnicas de Fidalgo e Bononi (1989).

A identificação botânica foi realizada por meio de comparação com material já devidamente identificado do acervo do HUVA e através da literatura especializada (LORENZI, 2002). Após a identificação, os exemplares foram incorporados ao HUVA com o $n^{\circ}$ de registro do herbário. 
O diagnóstico qualitativo foi efetuado in locu em 17 ruas. Os dados foram coletados através de um formulário pré-estruturado, coletando-se dados referentes às vias públicas e às espécies existentes sendo enumeradas as seguintes informações: (1) nome da rua; (2) nome vulgar da espécie; (3) nome científico (4) frequência na rua (5) condições físicas: boa (sem nenhum tipo de praga ou sinais de vandalismo ou poda drástica), satisfatória (com presença leve de pragas), ruim (ataque severo de

a. Diversidade:

$D Q_{\tau}=\frac{\pi f x}{n t f}$

Em que:

D\%: Diversidade

nfx: Número de espécies da família(x).

ntf: Número total de famílias.

Condições físicas, Necessidade de Poda e Área livre ao redor da base dos espécimes foram obtidas por meio de cálculos simples de porcentagem. Em que o número de cada amostra (quantidade que estava com condições físicas: boa ou quantidade que necessitava de poda pesada, etc.) é dividido pragas ou poda drástica) e morta; (6) necessidade de tratamento: poda leve, poda pesada; (7) área livre ao redor da base das árvores - ampla $(>1 \mathrm{~m})$, regular $(=1 \mathrm{~m})$, restrita $(<1 \mathrm{~m})$ e inexistente. Nesta fase da pesquisa além de observações e coletas foram feitos registros fotográficos. Os dados foram demonstrados em gráficos e calculados conforme metodologia adaptada a metodologia usada por Romani (2012), pelas fórmulas:

b. Percentual de espécies exóticas e nativas:

$$
\begin{aligned}
& s p Q \%=n(2 \times 0) / n t \\
& s p \%_{0}=n(n a t) / n t
\end{aligned}
$$

Em que:

$\mathrm{sp} \%$ : Percentual da origem das espécies. n(exo): Número de espécies exóticas. nt: Número total de espécies n(nat): Número de espécies nativas.

pelo número total de indivíduos arbóreos e multiplicado por 100 .

Apresenta-se ainda uma listagem das espécies com suas respectivas famílias, origens e frequência relativa da espécie na arborização no distrito, calculada da seguinte forma:

$$
\begin{gathered}
\qquad R \%=n t / n t \\
\text { Onde, } \\
\mathrm{FR}=\text { Percentual de Frequência Relativa } \\
\mathrm{ni}=\text { Número de indivíduos da espécie i } \\
\mathrm{nt}=\text { Número total de indivíduos. }
\end{gathered}
$$




\section{Levantamento fitossanitário}

O levantamento fitossanitário foi realizado por meio de amostragem de insetos de ocorrência nas árvores e observações visuais nas partes vegetativas e reprodutivas das mesmas durante as estações de inverno e de verão do ano de 2012. Foram feitas duas coletas de insetos, uma em cada estação, esta foi realizada aleatoriamente em 29 indivíduos arbóreos, englobando quatorze ruas dos povoados Pedrinhas, Ouro-branco e Recreio. Os insetos foram capturados com um guarda-chuva entomológico, utilizando-se vinte batidas nos ramos de cada planta, além de observações nos troncos.
Após a coleta, os insetos foram conduzidos ao Laboratório de Zoologia da Universidade Estadual Vale do Acaraú - UVA e posteriormente classificados a nível de Ordem e quando possível a nível de espécie, com auxílio da literatura entomológica e site especializado (GALLO et. al, 1988 ; INSTITUTO HÓRUS, 2012). A partir destas informações, elaborou-se uma tabela quantificando a presença e danos destes artrópodes.

\section{RESULTADOS E DISCUSSÃO}

Foram registrados na arborização do Distrito de Rafael Arruda no período estudado 1546 indivíduos distribuídos em 32 espécies e 15 famílias botânicas (Tabela I). Foi verificado que $72 \%$ das espécies que arborizam o distrito citado são exóticas, enquanto que apenas $28 \%$ são nativas, conforme a literatura consultada e no syte especiaizado (LISTA DE ESPÉCIES DA FLORA DO BRASIL, 2012).

Observando-se o número de indivíduos por espécies, constatou-se que $85 \%$ do total de exemplares pertencem a apenas três espécies representados pelo Nim (Azadirachta indica) com 800 indivíduos, sempre-verde (Ficus benjamina) com 164 indivíduos e a Acácia (Senna siamea) com 334 indivíduos em detrimento dos $25 \%$ dos exemplares que pertencem às 29 espécies.

Tabela 1. Listagem das espécies com suas respectivas famílias, freqüência e origem de ocorrência no Distrito de Rafael Arruda, Sobral, CE, Brasil, 2012

\begin{tabular}{|c|c|c|c|c|c|c|}
\hline \multirow[t]{2}{*}{ Espécie } & \multirow{2}{*}{$\begin{array}{l}\text { Nome } \\
\text { popular }\end{array}$} & \multirow[t]{2}{*}{ Família } & \multirow{2}{*}{$\begin{array}{c}\mathrm{N}^{0} \text { de } \\
\text { Indivíd } \\
\text { uos }\end{array}$} & \multirow{2}{*}{$\begin{array}{c}\text { Freq. } \\
\text { Relativa } \\
(\%) \\
\end{array}$} & \multicolumn{2}{|c|}{ Origem } \\
\hline & & & & & Nativa & Exótica \\
\hline $\begin{array}{l}\text { Albizia polyantha (Spreng. } \\
\text { F.) G.P }\end{array}$ & canafístula & Fabaceae & 4 & $0,26 \%$ & - & $\mathrm{x}$ \\
\hline $\begin{array}{l}\text { Anacardium occidentale } \\
\text { L. }\end{array}$ & cajueiro & Anacardiaceae & 51 & $3,30 \%$ & $\mathrm{x}$ & - \\
\hline $\begin{array}{l}\text { Anadenanthera pavonina } \\
\text { L. }\end{array}$ & carolina & Fabaceae & 2 & $0,13 \%$ & - & $\mathrm{x}$ \\
\hline
\end{tabular}




\begin{tabular}{|c|c|c|c|c|c|c|}
\hline Annona squamosa Lin. & ateira & Annonaceae & 27 & $1,75 \%$ & - & $\mathrm{x}$ \\
\hline Azadirachta indica.A.Juss & $\operatorname{nim}$ & Meliaceae & 800 & $51,75 \%$ & - & $\mathrm{x}$ \\
\hline Caesalpinia pulcherrima & $\begin{array}{l}\text { flamboyant- } \\
\text { mirim }\end{array}$ & Fabaceae & 4 & $0,26 \%$ & - & $\mathrm{x}$ \\
\hline Cassia fistula Linn. & $\begin{array}{l}\text { chuva-de- } \\
\text { ouro }\end{array}$ & Fabaceae & 2 & $0,13 \%$ & - & $\mathrm{x}$ \\
\hline Cocos nucifera L. & coqueiro & Arecaceae & 41 & $2,65 \%$ & $\mathrm{x}$ & - \\
\hline Crataeva tapia Lin. & trapiá & Brassicaceae & 6 & $0,39 \%$ & $\mathrm{x}$ & - \\
\hline $\begin{array}{l}\text { Delonix regia (Boj. Ex } \\
\text { Hook) Raf. }\end{array}$ & flamboyant & Fabaceae & 4 & $0,26 \%$ & - & $\mathrm{x}$ \\
\hline $\begin{array}{l}\text { Enterolobium } \\
\text { contortisiliquum (Vell.) } \\
\text { Morong }\end{array}$ & timbaúba & Fabaceae & 1 & $0,06 \%$ & $\mathrm{x}$ & - \\
\hline $\begin{array}{l}\text { Erythrina indica Lam. } \\
\text { "Picta" }\end{array}$ & brasileiro & Fabaceae & 29 & $1,88 \%$ & - & $\mathrm{x}$ \\
\hline Ficus benjamina Linn & $\begin{array}{l}\text { sempre } \\
\text { verde }\end{array}$ & Moraceae & 164 & $10,61 \%$ & - & $\mathrm{x}$ \\
\hline Hibiscus rosa-sinensis & hibiscus & Malvaceae & 1 & $0,06 \%$ & - & $\mathrm{x}$ \\
\hline $\begin{array}{l}\text { Leucaena } \\
\text { leucocephala.(Lam.) De } \\
\text { Wit. }\end{array}$ & leucena & Fabaceae & 2 & $0,13 \%$ & - & $\mathrm{x}$ \\
\hline Mangifera indica L. & mangueira & Anacardiaceae & 8 & $0,52 \%$ & - & $\mathrm{x}$ \\
\hline Nerium oleander L. & espirradeira & Apocynaceae & 8 & $0,52 \%$ & - & $\mathrm{x}$ \\
\hline Pachira aquatica Aubl. & monguba & Bombacacae & 3 & $0,19 \%$ & $\mathrm{x}$ & - \\
\hline $\begin{array}{l}\text { Pithecellobium Dulce ( } \\
\text { Roxb.) Benth. }\end{array}$ & mata fome & Fabaceae & 2 & $0,13 \%$ & - & $\mathrm{x}$ \\
\hline $\begin{array}{l}\text { Prosopis juliflora ( SW. } \\
\text { DC) }\end{array}$ & algaroba & Fabaceae & 7 & $0,45 \%$ & - & $\mathrm{x}$ \\
\hline Psidium guajava L. & goiabeira & Myrtaceae & 2 & $0,13 \%$ & $\mathrm{x}$ & - \\
\hline $\begin{array}{l}\text { Senna siamea (Lam.) } \\
\text { Irwin \&Barneby }\end{array}$ & acácia & Fabaceae & 334 & $21,60 \%$ & - & $\mathrm{x}$ \\
\hline Spondias cytherea Sonn & cajarana & Anacardiaceae & 6 & $0,39 \%$ & - & $\mathrm{x}$ \\
\hline Spondias purpúrea L & seriguela & Anacardiaceae & 5 & $0,32 \%$ & $\mathrm{x}$ & - \\
\hline $\begin{array}{l}\text { Syzygium jambolana } \\
\text { DC. }\end{array}$ & azeitona & Oleaceae & 1 & $0,06 \%$ & - & $\mathrm{x}$ \\
\hline $\begin{array}{l}\text { Tabebuia heptaphylla } \\
\text { (Vell) Toledo }\end{array}$ & $\begin{array}{l}\text { pau d'arco } \\
\text { rosa }\end{array}$ & Bignoniaceae & 3 & $0,19 \%$ & $\mathrm{x}$ & - \\
\hline Tamarindus indica $L$. & tamarindo & Fabaceae & 4 & $0,26 \%$ & - & $\mathrm{x}$ \\
\hline $\begin{array}{l}\text { Tecoma stans L. } \\
\text { juss.ex kunth }\end{array}$ & $\begin{array}{l}\text { ipezinho de } \\
\text { jardim }\end{array}$ & Bignoniaceae & 9 & $0,58 \%$ & - & $\mathrm{x}$ \\
\hline $\begin{array}{l}\text { Terminalia catappa } \\
\text { Linn. }\end{array}$ & castanhola & Combretaceae & 5 & $0,32 \%$ & - & $\mathrm{x}$ \\
\hline $\begin{array}{l}\text { Thespesia populaceae } \\
\text { Soland. }\end{array}$ & $\begin{array}{l}\text { algodão do } \\
\text { pará }\end{array}$ & Malvaceae & 2 & $0,13 \%$ & - & $\mathrm{x}$ \\
\hline $\begin{array}{l}\text { Thevetia peruviniana } \\
\text { Merril. }\end{array}$ & $\begin{array}{l}\text { chapéude } \\
\text { napoleão }\end{array}$ & Apocynaceae & 7 & $0,45 \%$ & - & $\mathrm{x}$ \\
\hline Zizyphus joazeiro.Mart & juazeiro & Rhamnaceae & 2 & $0,13 \%$ & $\mathrm{x}$ & - \\
\hline TOTAL & 32 & 15 & 1546 & $100 \%$ & 9 & 23 \\
\hline
\end{tabular}


Os dados da Figura 2 mostra que as famílias Fabaceae (38\%), Anacardiaceae (13\%) seguida de Malvaceae, Apocynaceae e Bignoniaceae com (6\%) apresentaram maior riqueza de espécies quando comparadas com as demais famílias encontradas no Distrito.

Figura 2. Frequência das Espécies por famílias utilizadas na Arborização do Distrito de Rafael Arruda, SobralCE

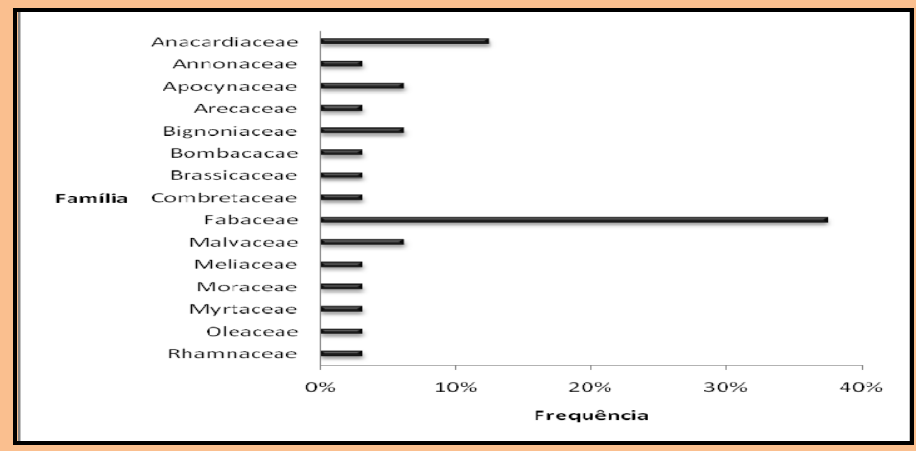

Com relação à fitossanidade, observa-se que $73,54 \%$ apresentaram-se em bom estado, sem nenhum sinal de praga ou vandalismo e com a forma natural de suas espécies, ou seja, apresentavam uma copa típica de sua espécie, enquanto que $22 \%$ apresentaram-se com ataques brandos de pragas, principalmente percevejos, que se mostraram causar pouco ou nenhum dano visível. Por outro lado, apenas 3,82\% das plantas observadas foram incluídas na condição ruim, apresentando severos danos ocasionados por pragas, danos físicos ou podas drásticas, enquanto $0,64 \%$ dos indivíduos se apresentaram mortas. Ao longo deste trabalho, verificou-se também alguns atos de vandalismos como nomes escritos com objetos cortantes/perfurantes, ramos quebrados, tampas de garrafas pet pregadas e cordas apertadas em volta de seus troncos (Figura 3).

Figura 3. Nomes escritos e cordas apertadas em troncos de árvores do Distrito de Rafael Arruda, Sobral - CE, 2012

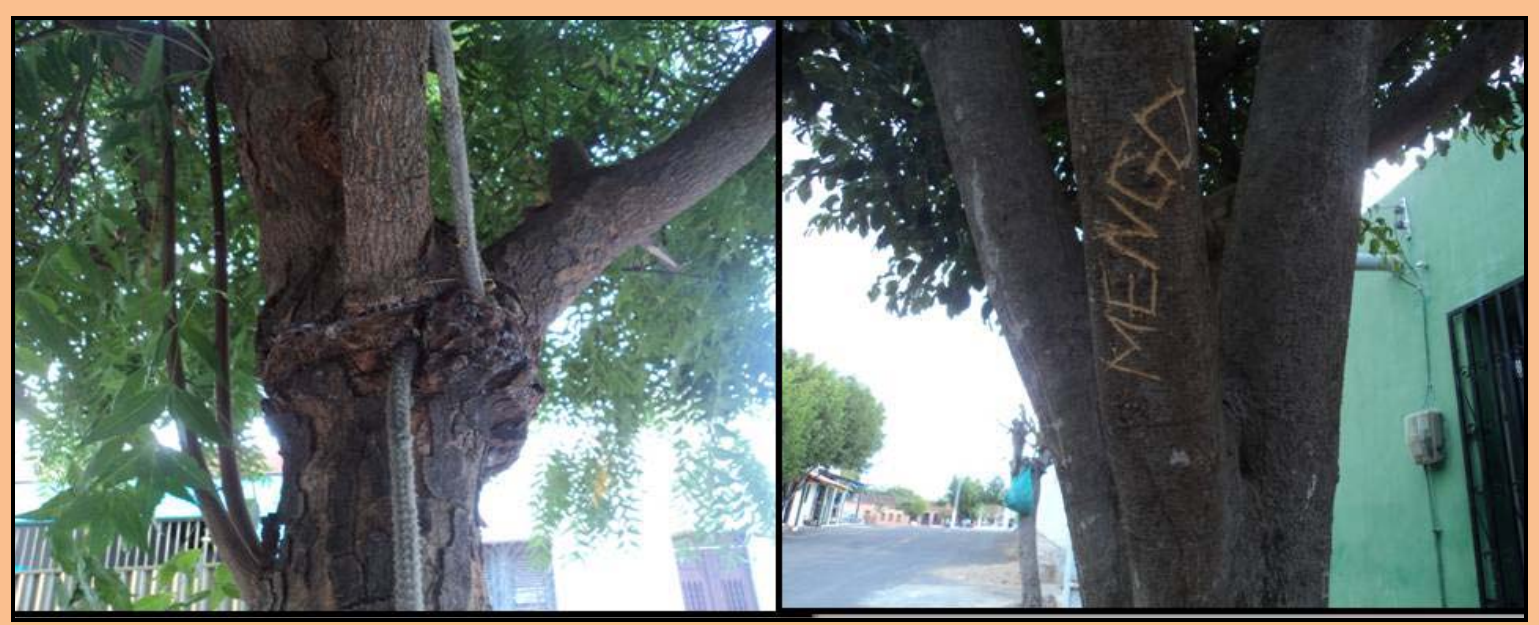

FONTE: SOUSA, L. M (2012) 
Com relação à necessidade de se fazer poda, observou-se que 9,38\% das plantas necessitava de poda leve, não estando adequado à visibilidade em estradas devido aos seus ramos secos, doentes e mal formados. E apenas 0,26 \% necessitavam de uma poda mais pesada, que mudasse sua estrutura típica, pois as mesmas estavam se entrelaçando nos cabos de energia elétrica. $90,42 \%$ dos indivíduos não necessitavam de qualquer tipo de tratamento.

No que se refere à área livre $23 \%$ apresentaram condição ampla, 11\% na condição regular, 30\% na condição restrita e 37\% na condição inexistente, ou seja, eram plantadas em calçadas ou plantadas numa distancia tão perto uma das outras que suas copas ficavam muito unidas.

As principais espécies de árvores amostradas, as espécies de insetos coletadas em cada uma delas e o número de ocorrência desses insetos e suas devidas ordens encontram-se na Tabela II.

Tabela 2. Ocorrência de insetos com suas devidas ordens nas principais árvores do Distrito de Rafael Arruda, Sobral, CE, 2012

\begin{tabular}{cccccccccc}
\hline & \multicolumn{3}{c}{$\begin{array}{c}\text { Ocorrência de Insetos por ordem a que pertencem } \\
\mathbf{1}^{\mathbf{a}} \text { Coleta }\end{array}$} \\
\hline $\begin{array}{c}\text { Espécie vegetal } \\
\text { Thy }\end{array}$ & Hem & Hym & Col & Thy & Hem & Hym Col \\
Senna siamea (Lam.) Irwin \& & 0 & 9 & 48 & 2 & 0 & 0 & 14 & 3 \\
Barneby & & & & & & & & \\
Anacardium occidentale L & 0 & 30 & 0 & 0 & 0 & 37 & 0 & 0 \\
Azadirachta indica A. Juss & 0 & 0 & 21 & 0 & 0 & 0 & 8 & 7 \\
Ficus benjamina Linn & 380 & 0 & 59 & 0 & 3 & 56 & 10 & 0 \\
Thevetia peruviniana Merril. & 0 & 1 & 2 & 1 & 0 & 0 & 0 & 0 \\
Erythrina indica Lam. "picta" & 0 & 15 & 3 & 0 & 0 & 0 & 11 & 0 \\
Pachira aquatica Aubl. & 0 & 0 & 24 & 0 & 0 & 0 & 0 & 0 \\
\hline TOTAL & 380 & 55 & 157 & 3 & 3 & 93 & 43 & 10 \\
\hline
\end{tabular}

TABELA II. THY: Ordem Thysanoptera; HEM: Ordem Hemiptera; HYM: Ordem Hymenoptera; Hom: Ordem Homoptera; COL: Ordem Coleoptera.

Quanto à fitossanidade, na primeira coleta feita em 29 árvores foram encontrados um total de 595 insetos, pertencentes a 4 ordens, a saber: Thysanoptera, Hemiptera, Hymenoptera e Coleoptera. Destas, a mais presente entre as árvores de Benjamim (Ficus benjamim Linn) amostradas na primeira coleta foi a Thysanoptera, que também apresentou a maior freqüência dentre as outras ordens encontradas (63,8\%). Esta ordem é causadora de muitos danos a essas plantas, onde as folhas mostraram-se muito enroladas, seiva sugada e com uma coloração mais clara, além de uma grande queda dessas folhas.

A segunda ordem que mostrou estar mais presente foi a Hymenoptera $(25,8 \%)$, a que pertencem às formigas, essas foram coletadas principalmente de LEVANTAMENTO QUALI - QUANTITATIVO DA ARBORIZAÇÃO... 
espécies vegetais de Acácia (Senna siamea) e nessa pesquisa foram os únicos tipos de insetos encontrados na árvore exótica Nim (Azadiracta indica) onde também se observou ser uma causadora de danos as plantas como o corte de folhas e brotos.

Na segunda coleta foram encontrados 149 insetos, sendo que dessa vez a ordem que mais se apresentou foi a Homoptera $(62,4 \%)$, merecendo destaque na Tabela II. Um exemplo disso são as moscas brancas (Aleurodicus cocois) que foram encontradas nos cajueiros (Anacardium occidentale) e nos Benjamins (Ficus benjamim) que são algumas das espécies mais apresentadas no local. Essas árvores apareceram com folhas muito enrugadas com coloração amareladas, amadurecimento irregular de frutos e presença de fumagina que é uma mancha preta geralmente causada por alguns tipos de fungos que se alimentam das secreções açucaradas das moscasbrancas.

Conforme a Tabela II, houve uma queda na quantidade de insetos na $2^{\mathrm{a}}$ coleta se comparada com a primeira, com uma grande substituição da ordem Thysanoptera pela Homoptera.

O levantamento florístico das arbóreas do Distrito de Rafael Arruda demonstrou que as espécies exóticas são as mais cultivadas em detrimento das espécies nativas. Segundo Dehnen-Shmutz et al (2007) apud Almeida (2009) esta forte tradição de usar espécies exóticas na arborização de ruas, praças e parques tem gerado uma descaracterização e simplificação ambiental dos municípios, levando a uma perda cultural e desvalorização das espécies nativas locais.

A flora nativa brasileira é muito rica e possui espécies de grande valor paisagístico. Tais espécies, além de já serem adaptadas as condições climáticas locais, asseguram a presença de referenciais paisagísticos regionais.

Azadirachta indica $(51,76 \%)$ e a Senna siamea $(21,60 \%)$ foram as espécies que se mostraram com maior frequência na localidade. Estes dados contrariam as afirmações de Milano e Dalcin (2000), os quais argumentam que cada espécie não deve ultrapassar $10-15 \%$ do total de indivíduos da população arbórea, para um bom planejamento da arborização urbana, considerando que a predominância de apenas uma espécie ou grupo de espécies pode facilitar a propagação de pragas.

Apenas 3,82\% das árvores foram incluídas na condição ruim, apresentando severos danos ocasionados por pragas, danos físicos ou podas drásticas. Embora esse número tenha sido pequeno, pode-se dizer que as mesmas já estão comprometidas, pois, de acordo com Silva et al., (2008), essas podas drásticas podem reduzir o tempo de vida das árvores, já que um grande número de raízes de pequeno calibre tem a sua eficiência reduzida.

Com relação à área ao redor da base das árvores, $37 \%$ apresentavam espaço inexistente, ou seja, eram plantadas em calçadas deixando suas raízes sem espaço ou plantadas numa distancia tão perto uma das outras que suas copas ficavam muito unidas. Uma árvore necessita de um espaço de crescimento tanto para a parte aérea, quanto para as raízes, bem como de área permeável para receber, ar, água e nutrientes (VELASCO, 2005). De modo a evitar danos provocados pelo sistema radicular das árvores, os planos de arborização de cidades deve-se respeitar a área livre mínima de $1,00 \mathrm{~m}^{2}$, inclusive para que possa ser realizada a irrigação e a adubação periódica (PIVETTA; SILVA FILHO, 2002; COELBA, 2002). O que não se observa nesta pesquisa. 
Com relação à fitossanidade, os indivíduos que se mostraram mais prejudicados foram fícus (Ficus benjamina) de origem exótica. Embora a maioria dessas espécies da amostra tenha apresentado pragas diferentes (com a troca de estação) como os da ordem Thysanopetra por Homoptera eles se mostraram resistentes as pragas. Os insetos da ordem Homoptera como as moscas brancas (Aleurodicus cocois) foram encontrados com maior freqüência na segunda coleta provavelmente devido ao período quente a que o Distrito é submetido e ao grande poder de dispersão que os insetos têm neste período, já que estes insetos são frágeis em umidade e se dispersam com ventos. A maioria das espécies onde foram encontrados os homópteros se encontrou com a coloração clara devido à seiva que era sugada, onde os insetos (adultos e ninfas) provocaram alterações no desenvolvimento vegetativo e reprodutivo das plantas, debilitando-as e reduzindo a suas qualidades. Além disso, foi observado que esses insetos perturbam a paz da população urbana, em suas moradias, praças e passeios com as suas revoadas causadas pelo vento.

Quanto às espécies nativas, as mesmas se mostraram em estado sanitário satisfatório confirmando a relação positiva das espécies da região e o clima da área.

\section{CONCLUSÃO}

- A arborização do Distrito apresentou baixa diversidade vegetal, alta frequência de espécies exóticas, além de podas emergenciais e inadequação entre o porte das árvores e o tamanho da área livre em volta das mesmas, demonstrando falta de planejamento urbano;

- Sugere-se um planejamento, ou melhor, forma de manejo para a arborização do Distrito de Rafael Arruda compreendendo principalmente a ampliação das áreas livres e a substituição gradual de $F$. benjamina e Azadiracta indica por espécies nativas e mais adequadas a passeios públicos. 


\section{AGRADECIMENTOS}

Ao Herbário Prof. Francisco José de Abreu Matos (HUVA) da Universidade Estadual Vale do Acaraú (UVA) e a comunidade do Distrito de Rafael Arruda pela colaboração durante as etapas do trabalho.

\section{REFERÊNCIAS BIBLIOGRÁFICAS}

ALMEIDA, W. R. et al. Contextualização sobre Espécies Exóticas Invasoras: Dossiê Pernambuco. AMANE/TNC/CEPAN/CI- Brasil, Recife-PE. 2009.

BOENI, B. O; SILVEIRA, D. Diagnóstico da Arborização Urbana em bairros do município de Porto Alegre, RS, Brasil. Revista SBAU, Piracicaba - SP, v.6, n.3, p.189-206, 2011.

CARVALHO, P. E. R. Espécies florestais brasileiras: recomendações silviculturais, potencialidades e uso da madeira. Colombo, PR: Embrapa Floresta, 2004. 640p.

CEARÁ. Instituto de Pesquisas e Estratégia Econômica do Ceará (IPECE). Perfil Básico Municipal: Sobral. Fortaleza, 2011.

COELBA. Guia de Arborização Urbana. Diretoria de Gestão de Ativos; Departamento de Planejamento dos Investimentos; Unidade de Meio Ambiente. Bahia, 2002. 56p.

FIDALGO, O; BONONI, V. L. R. Técnicas de coleta, preservação e herborização de material botânico. Instituto de botânica. São Paulo. 1989.

GALLO, D. et al. Manual de Entomologia agrícola. 2ed. Ceres, São Paulo, 1988. 649p.

GOOGLE. Programa Google Earth, 2012. Disponível em: http://www.google.com/earth/index.html, acesso em 28 nov. 2012.

INSTITUTO HÓRUS. Instituto Hórus de Desenvolvimento e Conservação Ambiental: Espécies Exóticas Invasoras. Disponível em: http://www.institutohorus.org.br/inf fichas.htm/, acesso em 17 fev. 2012.

LISTA DE ESPÉCIES. Lista de Espécies da Flora do Brasil, 2012. Disponível em: HTTP://floradobrasil.jbrj.gov.br/2012, acesso em 01/12/2012. 
LORENZI, H. Árvores Brasileiras. Manual de identificação e cultivo de plantas arbóreas nativas do Brasil. Nova

Odessa: Editora Plantarum, v.1, 4. ed. São Paulo: 2002.

MILANO, M.; DALCIN, E. Arborização de vias públicas. Rio de Janeiro: LIGHT, 2000. 226p.

PIVETTA, K.F.L.; SILVA FILHO, D.F.; Arborização urbana. Jaboticabal: UNESP/FCAV/FUNEP, 2002 , 69

p. (UNESP/FCAV/FUNEP. Boletim acadêmico).

ROMANI, G. N. et al. Análise Quali-Quantitativa da arborização da Praça XV de Novembro em Ribeirão Preto - SP, Brasil. Revista Árvore, Viçosa- MG, v.36, n.3, 2012, p. 479-487.

SANTAMOUR JÚNIOR, F. S. Trees for urban planting: diversity uniformity, and common sense. Agriculture Research Service. Washington: U.S. National Arboretum. 2002.

SANTOS, E. Avaliação quali-quantitativa da arborização e comparação econômica entre a poda e a substituição da rede de distribuição de energia elétrica da região administrativa centro-sul de Belo Horizonte, MG. 2000. 219p. Dissertação (Doutorado em Ciência Florestal). Universidade Federal de Viçosa, Viçosa, MG, 2000.

SILVA, L. M. et al. Inventário da arborização em duas Vias de Mariópolis/PR. Revista SBAU, Piracicaba, v.3, n.1, mar. 2008.

VELASCO, G. D. N.; LIMA, A. M. L. P. Danos em calçadas e sua relação com área permeável, circunferência à altura do peito (CAP) e poda em árvores urbanas. In: Congresso Brasileiro de Arborização Urbana 9, Anais... Belo Horizonte, 2005.

ZILLER, S. R. Os processos de degradação ambiental originados por plantas invasoras. Revista Ciência Hoje. n. 178, dez. 2001. 